\title{
Aspectos do cuidado integral para pessoas em situação de rua acompanhadas por serviço de saúde e de assistência social: um olhar para e pela terapia ocupacional
}

\author{
Fernanda Oliveira Mota ${ }^{a}$ (D), Rafaela Maria Alves Martins Fonseca ${ }^{b}$ (D), \\ Josenaide Engracia dos Santos ${ }^{\mathrm{b}}$ (1), Andrea Donatti Gallassi ${ }^{\mathrm{b}}$ (i) \\ a'Universidade Luterana de Palmas, Palmas, TO, Brasil.

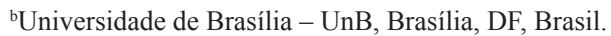

\begin{abstract}
Resumo: Introdução: A população que (sobre)vive nas ruas se caracteriza, muitas vezes, pela ruptura dos vínculos sociais e pelo uso de drogas, necessitando de cuidados de saúde e de assistência social. Objetivo: Identificar e analisar as percepções dos profissionais terapeutas ocupacionais e dos usuários sobre a atuação e especificidade da terapia ocupacional junto às pessoas em situação de rua atendidas pelo Centro de Atenção Psicossocial álcool e drogas (CAPS-ad III) e pela Unidade de Acolhimento (UA). Método: Trata-se de um estudo exploratório, de abordagem qualitativa, realizada a partir de entrevistas semiestruturadas com três terapeutas ocupacionais e cinco usuários de um CAPS-ad III do Distrito Federal e da UA referenciada por este CAPS-ad III; os dados foram analisados a partir do método de Análise de Conteúdo. Resultados: Os dados foram organizados em três categorias temáticas: (1) uso de drogas, a situação de morador de rua e o tratamento no CAPS-ad III; (2) o cotidiano de atuação da terapia ocupacional; e (3) terapia ocupacional e reinserção social. Conclusão: A terapia ocupacional atua com população em situação de rua com olhar para o cotidiano e desempenho de Atividades de Vida Diária (AVD), trabalhando na perspectiva da Redução de Danos como forma de buscar uma maior qualidade de vida dos usuários. Torna-se necessário levar espaços de saúde e de assistência social para o contexto do usuário, realizar ações extrapolando o espaço físico do CAPS-ad e colocando o usuário como participante ativo desse processo.
\end{abstract}

Palavras-chave: População em Situação de Rua, Drogas de Abuso, Terapia Ocupacional.

\section{Aspects of the whole care for people in street followed by health and social assistance services: a look at and for occupational therapy}

\begin{abstract}
Introduction: The population that lives (survive) on the streets is often characterized by the rupture of social ties and the use of drugs, necessitating health care and social assistance. Objective: To identify and analyze the perceptions of the occupational therapist professionals and the users about the performance and specificity of the occupational therapy with the street people assisted by the community-based drug treatment service (CAPS-ad III) and the Embracement Unit (EU). Method: This is an exploratory and qualitative study based on semi-structured interviews with 3 occupational therapists and 5 users of a CAPS-ad III from the Federal District and the Embracement Unit (EU) referenced by this CAPS-ad III; the data were analyzed using analysis content. Results: The data were organized into three thematic categories: (1) drug use, homelessness and treatment in CAPS-ad III; (2) the daily routine of Occupational Therapy; (3) Occupational Therapy and
\end{abstract}

Autor para correspondência: Andrea Donatti Gallassi, Universidade de Brasília, Campus Ceilândia, Centro Metropolitano 1, Conjunto A, Ceilândia Sul, CEP 72220-140, Brasília, DF, Brasil, e-mail: andrea.gallassi@gmail.com

Recebido em Out. 17, 2018; $1^{\text {a }}$ Revisão em: Fev. 18, 2019; 2a Revisão em: Abr. 10, 2019; Aceito em: Maio 12, 2019. 
Social Integration. Conclusion: The Occupational Therapy acts with the population in a street situation with a look at the daily life and performance of Activity of Daily Living (ADL), working in the perspective of Harm Reduction as a way to seek a higher quality of life of users. It is necessary to take care spaces and social assistance to the user context, to take actions extrapolating the physical space of CAPS-ad and placing the user as an active participant in this process.

Keywords: Homeless Persons, Street Drugs, Occupational Therapy.

\section{Introdução}

A população que (sobre)vive nas ruas vem aumentando por diversos motivos, tais como: situação de pobreza, desemprego, rupturas dos vínculos familiares e das redes sociais de suporte, migraçóes face a violência urbana, e/ou uso problemático de álcool e outras drogas (SILVA et al., 2018).

Em países da Europa e no Brasil, as respostas institucionais frente a esta questão, historicamente compuseram o rol de açôes da assistência social a partir de uma abordagem assistencialista e pouco problematizada sobre os elementos constituintes do fenômeno. Especialmente no Brasil, a partir da década de 1960, o debate passa, então, a ser compreendido de uma perspectiva sanitária, "medicalizante", que mantém o estreitamento da compreensão de sua complexidade passando a considerá-la partir de um diagnóstico médico, recrudescendo a perspectiva higienista de remoção de populaçôes indesejadas dos centros urbanos. Tal compreensão acaba por ser reproduzida pelos próprios serviços de saúde (FOUCAULT; ALVAREZ-URÍA; VARELA, 1992; VARANDA; ADORNO, 2004; AMARANTE, 2007).

A visibilidade que a população em situação de rua (PSR) adquiriu, exigiu do Estado políticas públicas que pudessem responder às suas necessidades, que eram, até entáo, ignoradas. O parágrafo único da Política Nacional para a Populaçáo em Situação de Rua (PNPSR) a define:

[...] grupo populacional heterogêneo que possui em comum a pobreza extrema, os vínculos familiares interrompidos e/ou a inexistência de moradia convencional regular, e que utiliza os logradouros públicos e as áreas degradadas como espaço de moradia e de sustento, de forma temporária ou permanente, bem como as unidades de acolhimento para pernoite temporário ou como moradia provisória (BRASIL, 2009a).

A PNPSR versa sobre os direitos desta população, incluindo o respeito à pessoa humana, direito à convivência familiar e comunitária, valorização e respeito à vida e cidadania. Além destes, é destacado o direito à saúde, ao atendimento pelos diversos serviços e categorias profissionais e de forma humanizada, visando também a concretização dos princípios de equidade, universalidade, integralidade e igualdade do Sistema Único de Saúde (SUS) (BRASIL, 2009a).

A compreensão do processo saúde-doença se constitui ferramenta indispensável para a definição das açôes do setor saúde junto à PSR. As práticas, no entanto, acabam por ocorrer somente em situaçóes de emergência e realizadas, muitas vezes, por profissionais sem o devido preparo técnico; esta abordagem, porém, deve, necessariamente, ocorrer a partir da compreensão de fatores que extrapolam o universo da saúde e dialoguem com os aspectos sociais e da cultura de rua, a história de vida dessas pessoas e suas estratégias de sobrevivência. O Consultório na Rua, dispositivo de cuidado que compóe a atenção básica em saúde, foi criado com o objetivo de prestar atendimento in loco à PSR numa perspectiva menos emergencial, mas de acompanhamento contínuo e prevenção realizado por profissionais capacitados. $\mathrm{O}$ estar vivo, muitas vezes, é o necessário para se considerar com saúde, e a doença passa a ser compreendida somente quando se encontram em uma situação debilitante que os impeça de trabalhar para ganhar dinheiro e garantir sua sobrevivência (PAIVA et al., 2016; SILVA; FRAZÃO; LINHARES, 2014).

Dentre as políticas públicas de saúde voltadas para a PSR, destaca-se a Portaria 3.088 (BRASIL, 2011) que instituiu a Rede de Atenção Psicossocial (RAPS), composta por serviços articulados que buscam uma atenção integral para pessoas com transtorno mental e/ou com necessidades decorrentes do uso de crack, álcool e outras drogas no âmbito do SUS. Dentre os serviços especializados que compóem a RAPS, o Centro de Atenção Psicossocial (CAPS) se configura como um articulador desta rede, classificados como I, II, III (24 horas), i (infantil) ou ad (álcool e drogas), variando de acordo com número de habitantes do município e o público alvo.

O CAPS-ad III, um dos objetos deste estudo, é um serviço portas abertas, de funcionamento 24 horas que oferece atendimento aos que dele necessitam e sua família. Possui equipe multidisciplinar 
formada, majoritariamente, por enfermeiros, assistentes sociais, médicos, psicólogos e terapeutas ocupacionais. Conta com leitos de retaguarda para desintoxicação - denominados de acolhimento integral - onde o usuário pode permanecer por até 14 dias, de acordo com sua necessidade clínica e social, participando das atividades do CAPS-ad III durante o dia (acolhimento diurno) e permanecendo no serviço também durante a noite. Neste serviço, a terapia ocupacional atua no cotidiano destas pessoas, buscando ampliar e retomar seu repertório de atividades com vistas à maior participação social e consequente diminuiçáo ou interrupção do uso de álcool ou outras drogas (GALLASSI et al., 2016). No caso das pessoas em situação de rua e que são atendidas no CAPS-ad, há uma série de questóes específicas relacionadas aos cuidados de saúde e às rupturas sociais, o que torna ainda mais desafiadora a intervenção (ANDRADE et al., 2011).

Outro ponto de atenção que integra a RAPS, segundo objeto de estudo, é a Unidade de Acolhimento (UA). Trata-se de um serviço de caráter residencial transitório, cujo objetivo é oferecer acolhimento voluntário e cuidados contínuos para pessoas com necessidades decorrentes do uso de crack, álcool e outras drogas, em situação de extrema vulnerabilidade social e familiar e que demandem acompanhamento terapêutico e protetivo. Os critérios para acessar a UA são: ter um Plano Terapêutico Singular (PTS) preestabelecido junto à equipe do serviço de referência que o encaminhou (que inclui, quando for o caso, além da permanência na UA o tratamento no CAPS-ad ou em outro serviço da RAPS), estar em busca de trabalho, estudo, ou como meio temporário para reorganização de vida (BRASIL, 2011). Ou seja, residir na UA é parte do PTS do usuário, tanto no que se refere ao tratamento pelo uso de álcool ou outras drogas, quando for o caso, quanto às estratégias de reinserção social, elementos que se articulam e são imprescindíveis para o processo de reabilitação psicossocial dessas pessoas, diferenciando-se do simples abrigamento noturno realizado pelos dispositivos de assistência social.

As atividades de tratamento que os usuários residentes da UA realizam, são estabelecidas pela equipe do serviço de referência, e podem não incluir sua frequência diária ao tratamento, considerando que parte de suas necessidades de saúde e social requer articulaçóes comunitárias para a busca de emprego, retomada dos laços familiares, na maioria das vezes rompidos, e moradia. Ao final do dia, os usuários devem retornar à UA em um horário pré-determinado (de acordo com o PTS) e não devem estar sob efeito de álcool ou de outras drogas. Em outras palavras, a
UA funciona como uma espécie de "república" e em uma estrutura física independente, porém próxima, do CAPS-ad III que a referencia; os afazeres domésticos são compartilhados e as regras estabelecidas pelos próprios residentes, cabendo à equipe do CAPS-ad III atuar como mediadora das relaçóes interpessoais e apoio para o cumprimento do PTS.

Em ambos os serviços - CAPS-ad III e UA - o desafio das profissóes é buscar a sua especificidade e identidade, dada a complexidade e intersecção das demandas sociais e de saúde (BOCCARDO et al., 2011). Coloca-se, portanto, a necessidade e o desafio dos profissionais, dentre eles o terapeuta ocupacional, que atuam neste campo de relação entre a saúde e o social, de elaborar, discutir e implementar açóes de acordo com as necessidades locais e dos usuários, tendo claro o objetivo de efetivar políticas públicas pautadas pelos direitos sociais e de saúde (MALFITANO; BIANCHI, 2013).

O objetivo deste estudo é identificar e analisar as percepçóes dos profissionais terapeutas ocupacionais e dos usuários sobre a atuação e especificidade da terapia ocupacional junto às pessoas em situaçáo de rua atendidas pelo Centro de Atenção Psicossocial álcool e drogas (CAPS-ad III) e pela Unidade de Acolhimento (UA).

\section{Método}

Trata-se de um estudo exploratório de abordagem qualitativa. Foram entrevistados três profissionais terapeutas ocupacionais que atuam em um CAPS-ad III do Distrito Federal (DF) e cinco usuários que estavam residindo temporariamente na UA e faziam tratamento neste CAPS-ad III.

O DF conta com 07 CAPS-ad, sendo três com funcionamento $24 \mathrm{~h}$ e que contam com leitos de retaguarda para desintoxicação (acolhimento integral), e atendem adultos e adolescentes a partir de 16 anos em uso problemático de álcool e outras drogas; 05 CAPS "transtorno", para adultos com outros transtornos mentais que náo relacionados ao uso problemático de álcool e outras drogas; 03 equipes de Consultório na Rua, que atuam, especialmente, em cenas urbanas de uso de álcool e outras drogas; 02 CAPS $i$, para crianças e adolescentes com transtornos mentais; 02 enfermarias psiquiátricas em hospitais gerais; 01 hospital psiquiátrico e 01 UA adulto. Os CAPS funcionam com portas abertas e são os principais articuladores da rede psicossocial do DF, encaminhando os usuários quando necessário para os demais serviços que compóem a RAPS. 
Os critérios de inclusão para os profissionais participarem do estudo foram: terem formação em terapia ocupacional, estarem atuando no CAPS-ad III que referencia a UA, desenvolverem açóes de cuidado com usuários que se encontram em situação de rua e aceitarem participar do estudo mediante a assinatura do Termo de Consentimento Livre e Esclarecido (TCLE). Os critérios de inclusão para os usuários foram: estarem em tratamento no CAPS-ad III, estarem em situação de rua quando acolhidos no serviço, residir temporariamente na UA referenciada por este CAPS-ad III, serem acompanhados por terapeuta ocupacional, e aceitarem participar do estudo mediante a assinatura do TCLE.

Para a coleta de dados, foi elaborado um roteiro de entrevista semiestruturada (MINAYO; SANCHES, 1993), composto por 24 questôes que abordavam com os profissionais terapeutas ocupacionais sobre a rotina do serviço, a atuação da equipe multidisciplinar, as demandas dos usuários em situação de rua, a relação interprofissional, bem como os desafios e as experiências positivas na relação terapêutica com estes usuários. O roteiro de entrevista com os usuários foi distinto do utilizado com os profissionais, e contou também com 24 questóes que abordavam sobre a vida anterior ao início do tratamento no CAPS-ad III, o contexto de situação de rua em que estavam inseridos, as demandas prioritárias, a visão sobre a equipe multidisciplinar, a visão específica sobre a terapia ocupacional e a experiência na UA.

A coleta de dados ocorreu entre o período de outubro a novembro de 2017. Com os profissionais, foi realizada no espaço do CAPS-ad III de forma individual de acordo com a disponibilidade de cada participante; com os usuários, a coleta ocorreu no espaço da UA, também individualmente. A definição dos espaços para a coleta de dados foi determinada levando em consideração o que seria mais conveniente para os participantes segundo eles próprios. Todas as entrevistas foram gravadas em áudio para posterior transcrição. As entrevistas com os usuários ocorreram após as entrevistas com os profissionais e todas as perguntas norteadoras do roteiro de entrevistas aos profissionais foram correlacionadas às perguntas feitas aos usuários, para possibilitar uma maior compreensão acerca do tratamento, como também para realizar possíveis relaçôes comas informaçóes obtidas.

A análise dos dados foi feita pelo método de Análise de Conteúdo de Bardin (2009), que compreende um conjunto de técnicas, e foi realizada em duas etapas: na primeira, a partir da marcação de palavras chaves a fim de identificar possíveis categorias de análise; na segunda, as categorias que emergiram foram discutidas à luz dos referenciais teóricos que fundamentaram essa pesquisa - a abordagem psicossocial de pessoas em situação de rua e que fazem uso problemático de drogas, e o cotidiano de atuação do terapeuta ocupacional junto a esta população. Os dados foram organizados em planilha categorial.

Este estudo foi aprovado pelo Comitê de Ética em Pesquisa (CEP) com parecer número 1.081.907/2015. Foi entregue no momento da entrevista o TCLE para assinatura dos participantes, bem como, o termo de autorizaçáo de uso de som de voz para fins de pesquisa. Os nomes dos participantes foram mantidos em sigilo, utilizando somente referência à fala de acordo com a ordem de entrevista.

\section{Resultados}

De acordo com a ordem de entrevista, os usuários foram nominados como Usuário 1, Usuário 2, Usuário 3, Usuário 4 e Usuário 5 e tinham idade de 29, 47, 52, 26 e 57 anos, respectivamente; todos eram do sexo masculino, estavam em situação de rua há mais ou menos 6 meses, 5 anos, 15 anos, 1 ano e 21 anos, respectivamente; estavam residindo na UA há mais ou menos 3 meses, e eram assistidos pelo CAPS-ad III há pelo menos 6 meses frequentando o serviço ao menos 3 vezes por semana. Estes usuários relataram que o principal motivo que os levaram a viver nas ruas foi o uso de álcool e outras drogas e a consequente desavença familiar; referem que tiveram tentativas anteriores de retornarem às casas de suas famílias, mas, novamente, por conta do uso, os conflitos se intensificaram e a saída de casa acabou sendo inevitável.

Os profissionais de terapia ocupacional eram do sexo feminino e também foram nominados de acordo com a ordem das entrevistas, sendo Profissional 1, Profissional 2 e Profissional 3, com idades de 26, 35 e 21 anos, respectivamente. O tempo de formação de cada uma foi de 4, 13 e 1 ano(s), respectivamente, e a área de formação complementar foi saúde mental (residência), hospitalar (aprimoramento) e a última estava cursando a residência em saúde mental. As duas primeiras eram servidoras da Secretaria de Estado da Saúde do DF (SES/DF) e atuavam no CAPS-ad III há 5 anos, e a última há 6 meses.

Os dados foram organizados em três categorias temáticas, sendo que a primeira e a terceira emergiram das entrevistas com os usuários, e a segunda e a terceira das entrevistas com os profissionais: (1) uso de drogas, a situação de morador de rua e o tratamento no CAPS-ad III; (2) o cotidiano de 
atuação da terapia ocupacional; (3)terapia ocupacional e reinserção social.

\subsection{Uso de droga, a situação de morador de rua e o tratamento no CAPS-ad III}

A vida na rua se configurou como um marco para esses usuários. Relataram que não tinham a percepção real sobre o que era estar em situação de rua e da exposição às situaçóes de violência e ao uso de drogas. Relacionaram um aumento no padráo de consumo com as perdas sofridas, como no trabalho e, especialmente, na família, buscando a substância muitas vezes para tapar um vazio existente. Alguns referiram a sensação de medo por não saberem o que aconteceria no dia seguinte, se iam ter o que comer ou se iam estar vivos, por passarem cotidianamente por diversas situaçôes de violência:

Eu tenho filhos né, me afastei para não prejudicar a eles, nem a mim nem a eles né, principalmente a eles. Eles sabem que eu estou em Brasilia, mas, não tenho contato, face, whatsapp. Não tenho contato de nada sabe, pra não atrapalhar a vida deles eu larguei de mão, já fiquei em situação de rua, mas nunca procurei eles não (Usuário 5).

O Usuário 1 relata que tinha uma vida "normal", trabalhava, mas não possuía mais vínculos com a família, porque saiu de casa muito novo e não tinha bom relacionamento com os irmãos, que eram usuários de drogas. Refere ter estudado e construído uma carreira: fez curso técnico na área da saúde e trabalhou em laboratórios como Exame e Pasteur. Começou a usar drogas por influência de amigos e com o tempo passou a fazer uso pesado, principalmente de cocaína, o que o levou aos "corres" no centro de Taguatinga (Regiẫo Administrativa do DF), segundo ele, para roubar, traficar e se prostituir, sendo a partir desta experiência que passou a viver realmente na rua.

Atualmente fez um exame e descobriu uma doença sexualmente transmissível (sífilis) e isso o deixou bastante assustado: "graças ao tratamento do CAPS eu descobri e estou tratando essa doença". A descoberta do serviço para esse usuário foi aleatória:

Fui na agência do trabalhador e me deparei com o CAPS, e busquei ajuda; vim no CAPS e fiz acolhimento com a Marial e contei a minha história; também contei que tentei suicídio (Usuário 1).

A partir dos relatos, observa-se que os usuários não tinham a compreensão exata sobre o funcionamento do CAPS-ad III. Chegaram por indicação de terceiros, de familiar, ou por demanda espontânea, e ouviram comentários ruins sobre esse tipo de serviço, relacionando-o à prisão e ao tratamento para "gente doida”, não entendendo, de início, o seu objetivo; quando passaram a frequentá-lo, ficaram surpresos com a abordagem:
Pra mim, émeu porto seguro, pode ser exagerado, mas assim... Em toda a minha vida eu nunca tive amor, apesar que eu também não sei se tenho amor no CAPS, mas aparenta ser. Me acolhem, me escutam, me medicam, cuidam de mim, e isso me ajuda muito pro meu $E G O$, até para o meu próprio vício, porque eu acho que quando temos um vício é a perda de alguma coisa, é a perda de algo que você não consegue saber o que é. Vocêfica naquela busca infinita (Usuário 2).

Sobre a atuação da equipe multidisciplinar, de uma maneira geral, os usuários relataram que a assistência é adequada e os profissionais estão sempre disponíveis para ouvi-los.

Aqui no CAPS eu tenho achado isso, eu me emociono porque vejo a vontade das pessoas, e já fui muito maltratado. Quando vejo o ato de gentileza comigo, dá vontade de pegar no colo sabe, e caminhar (Usuário 2).

Porém, relatam que há algumas exceções:

Eu vejo um trabalho muito bom, pessoas acolhedoras, profissionais de excelência. Tem seus profissionais que estão somente pelo dinheiro, mas tem também aqueles que estão aqui por amor à profissão, sempre poderá contar com eles, estäo sempre abertos ao diálogo, a um conselho. Resumindo eu os vejo muito humanos e muito profissionais (Usuário 1).

\subsection{O cotidiano de atuação da terapia ocupacional}

De acordo com a fala das profissionais, o serviço possui uma grande demanda diária, principalmente por funcionar 24 horas, e todos os usuários que chegam são acolhidos (serviço porta aberta). Neste momento do acolhimento é que acontece a escuta qualificada, o levantamento dos objetivos terapêuticos e a elaboraçáo do PTS, de acordo com as demandas e interesses do usuário:

A partir do momento que ele entra no acolhimento inicial, a gente faz avaliação, escuta e verifica quais são as demandas e prioridades dele, e damos os devidos encaminhamentos (Profissional 1).

$\mathrm{Na}$ elaboração do PTS, o usuário poderá ser encaminhado para o acolhimento diurno ou para 
o acolhimento integral. No acolhimento diurno, ele passa o dia em tratamento no serviço, participando dos grupos, oficinas e sendo assistido pela equipe de acordo com suas necessidades, e a noite ele volta para casa; nesta modalidade, ele terá acesso às refeições oferecidas pelo serviço.

O usuário será encaminhado ao acolhimento integral (leitos de retaguarda para desintoxicação) de acordo com sua necessidade clínica e situação de vulnerabilidade social. Nesta modalidade, além de participar do acolhimento diurno, ele passará a noite no serviço e poderá ficar até 14 dias "internado", podendo ser prorrogado se houver necessidade:

A gente sugere o acolhimento integral quando tem demanda, que geralmente são mais físicas, conflitos psicológicos e também pessoas que estão em situação de rua, a gente considera muito a vulnerabilidade, né (Profissional 3).

Quanto à elaboração PTS, instrumento norteador de todo o tratamento do usuário no serviço, há profissional que acredita que quando se trata de usuários em situação de rua, esta elaboração seria mais complexa pelo fato de, muitas vezes, estarem com os vínculos familiares fragilizados ou rompidos, e por não terem objetivos tấo claros quando chegam à unidade. No entanto, outras profissionais acreditam que por ser singular e elaborado de acordo com cada caso, não se difere muito dos demais.

De acordo com as profissionais entrevistadas, a demanda prioritária dos usuários em situação de rua que chegam ao serviço é de abrigamento. É bastante marcante a fala de que o usuário que busca um espaço protegido vê o CAPS-ad III e a UA como sendo estes espaços:

A demanda principal muitas vezes é de abrigo né, nem sempre ele quer tratar a droga, mas às vezes ele quer um abrigo. Ou às vezes ele tá fugindo de situação de violência (Profissional 2).

Quando há demanda de abrigamento, são feitas as articulaçôes necessárias para que esse usuário tenha um espaço de moradia e condiçôes mínimas para continuar o tratamento. A dificuldade encontrada neste momento é a de conseguir um espaço que seja realmente protegido, pois os próprios usuários relatam que não se sentem seguros em determinados serviços da rede. Ao realizarem a busca pelos locais disponíveis, as profissionais dão preferência pelos abrigos, seguidos das comunidades terapêuticas, posteriormente a própria UA e, caso o usuário tenha demanda, o acolhimento diurno do CAPS-ad III. O acolhimento diurno (passar o dia no serviço) é colocado como última estratégia para esse público, pois, muitas vezes, mesmo estes usuários estando em situação de rua, não há a demanda de permanência no serviço durante o dia todos os dias, e pela perspectiva da Redução de Danos, os usuários poderão acessar o serviço para demandas simples, como banho e alimentação, bem como para o uso de medicação. $\mathrm{O}$ acolhimento diurno é indicado para os dias em que as pessoas que fazem tratamento no CAPS-ad III tem atividades/atendimentos programados.

Quanto ao encaminhamento de usuários para UA e a própria compreensão sobre os objetivos deste serviço, os relatos são divergentes. Uma(s) profissionai(s) refere $(\mathrm{m})$ o local como uma unidade apenas para abrigamento temporário; outra(s) o categoriza $(\mathrm{m})$ como dispositivo de reinserção social:

Se fosse para destacar quais os serviços da rede intersetorial que mais nos acessam, temos a Casa Santo André, com serviço de abordagem na rua, que faz parte da SEDESTMIDH [Secretaria de Estado do Trabalho, Desenvolvimento Social, Mulheres, Igualdade Racial e Direitos Humanos], que é da rede mesmo de assistência social. Tem encaminhamentos da UNAF que é um dos abrigos do DF e também temos encaminhamentos de comunidades terapêuticas que possuem equipes atuando no território, ai trazem os pacientes com o intuito de conseguirem encaminhamentos para o abrigamento (Profissional 1).

A terapia ocupacional atua em ambos os serviços - CAPS-ad III e UA - estando com os usuários desde o primeiro contato. De acordo com as entrevistadas, há um olhar social e integral para os usuários, e quando se trata de uma pessoa em situação de rua, já no acolhimento se busca ter o conhecimento sobre o desempenho nas AVDs, visando sua autonomia e independência.

\subsection{Terapia ocupacional e reinserção social $^{2}$}
A TO nesse público a depender do individuo, a gente trabalha a questão da reinserção social, pois muitas vezes é um público que realmente não tem esse manejo de estar desempenhando essas atividades básicas e ai a gente tenta junto com o paciente fazer esse contato, junto com a rede, ou familiares e amigos e até mesmo dentro do nosso serviço para facilitar realmente o desempenho ocupacional (Profissional 1).

A busca pela reinserção social é bem marcante no serviço de uma maneira geral, e quando se trata de usuário em situação de rua, essa preocupação é 
ainda maior, visto que ele está, muitas vezes, em condição de extrema vulnerabilidade:

Às vezes a questão não é nem tirar ele da rua, porque muitas vezes ele não quer sair da rua, mas também de tornar a vida dele mais digna e melhor possivel, explorando os potenciais que ele tem. Eu acho a TO muito importante nesse campo ai (Profissional 2).

Expectativa que a gente tem, enquanto pessoa que tem que ter uma casa, um teto, um trabalho. Isso causa algumas frustraçôes, ai a gente percebe o quanto é importante trabalhar dentro da lógica de redução de dados. Dificilmente a gente percebe no dia a dia, que pacientes que moram na rua conseguem a abstinência. Ai temos que lidar com toda a nossa construção cultural do que seria o ideal para quem está na rua, ou para quem é usuário de substância, acho que isso é o que mais impacta com relação ao plano terapêutico (Profissional 1).

As principais dificuldades relatadas pelas profissionais quanto à atuação com esse público, foram acerca da adesão do usuário ao serviço, a rede pouco fortalecida para atendê-lo, poucos profissionais de terapia ocupacional atuantes na área, o próprio manejo com a equipe e, principalmente, quanto à rotina do serviço:

Um projeto especifico, acho que seria até interessante, por exemplo, uma equipe que esteja familiarizada com isso pra dar atenção a eles, porque assim, o CAPS éde base territorial, então uma equipe pra ir mesmo até esse território, conhecer essas pessoas, tentar trazer para os serviços, ou entäo tentar levar espaços de saúde para lá (Profissional 2).

Mas é, não só isso, eu acho que também assim, a demanda da rotina do serviço, eu por ser residente, é uma carga horária muito grande, mas não dá pra ser revertida em um maior estudo de um local onde essas pessoas estäo, $e$, de conhecer. A gente acaba sendo atropelada pela demanda institucional do serviço e aí não dá tempo de a gente ir ao território conhecer essas pessoas, ver as principais demandas, fazer uma abordagem com eles mesmos, onde as relaçóes acontecem, a gente fica muito restrito aqui, ao espaço, e a demanda do serviço (Profissional 3).

Para avaliar a percepção dos usuários quanto à atuação do terapeuta ocupacional no serviço, foram abordadas duas questôes específicas: "O que é a terapia ocupacional para você?? Você consegue identificar quais são as atuaçôes específicas da terapia ocupacional no serviço?" Mesmo os usuários que náo compreendiam sobre a profissão, definiram como "trabalhar metas e objetivos" e "ocupar a mente". Somente dois dos cinco usuários entrevistados conseguiram explicar de uma forma mais ampla o que seria o trabalho da terapeuta ocupacional no serviço.

Pra mim a terapia ocupacional é aquela pessoa que se depara com uma pessoa numa situação de risco, por exemplo, álcool ou drogas, e ela tenta deixá-la à vontade para expor o problema dela pra ela conseguir entrar com uma solução, com uma luz no final do túnel, com uma esperança para aquela pessoa, porque muitas vezes quem está dentro da situação não tem esperança nenhuma em conseguir se tratar, conseguir se reintegrar na sociedade. Então eu vejo a terapia ocupacional como isso, como a reintegração na sociedade, um trabalho mental mesmo (Usuário 1).

Não sei. Conheço a terapeuta ocupacional Nara ${ }^{3}$, muito gente boa, que me assiste, me vigia, a que toma conta. A Nara tá sempre visando meus objetivos, traçando meus objetivos, procurando saber como eu tô fazendo, como devo fazer como devo proceder. Isso que eu acho que é uma terapeuta ocupacional, ocupar-se e procurar melhoras para o outro (Usuário 2).

Por fim, foi destacado que a UA funciona como um importante dispositivo da RAPS para acolher essas pessoas que estão em situação de rua:

Bom, eu considero uma preparação pra você voltar a sociedade né. Ter uma visão diferente né, de permanecer sóbrio, e ter autonomia pra tudo. Graças a Deus tenho metas para serem cumpridas, mas nós temos autonomia, porque pra gente aqui é importante porque aprende a viver em comunidade, aprende a viver, cada um tem sua função, seu quarto, então aqui você aprende para quando você morar sozinho, você aprende né (Usuário 5).

Ao final das entrevistas, os usuários ressaltaram a necessidade de continuidade do tratamento no CAPS-ad III, mesmo após a saída da UA, pois entendem que o uso problemático de álcool e outras drogas é uma questão de saúde a ser cuidada a médio e longo prazo. Ainda que consigam um emprego e uma moradia, pretendem seguir frequentando o serviço.

\section{Discussão}

Para os usuários participantes, a condição de exclusão para a vida nas ruas ocorreu como uma das consequências do uso problemático de álcool e outras drogas. Essa associação e o perfil dos usuários 
do estudo se assemelham aos dados de outro estudo (ALVAREZ; ALVARENGA; RINA, 2009) e da Pesquisa Nacional sobre População de Rua, que estima que 31.922 adultos vivem nesta situação, sendo $82 \%$ do sexo masculino, e tendo como principais motivos problemas relacionados ao uso de álcool ou outras drogas $(35,5 \%)$ e as desavenças familiares (29\%) (BRASIL, 2009b).

A ruptura dos vínculos familiares é outro fator que se destaca como determinante para essas pessoas viverem nas ruas. Em um estudo de revisão de literatura, foi demonstrado que as relaçóes familiares tem forte associação na relação com o uso de álcool e outras drogas, podendo ser fator de risco ou de proteçáo; quando a relação familiar é conflituosa, com brigas constantes, torna-se um fator de risco, gerando o afastamento de seus membros (VASCONCELOS et al., 2015).

A frustração diante da realidade vivenciada e as dificuldades para planejar projetos futuros, resultam, muitas vezes, em disparadores para o uso de álcool e outras drogas; compreende-se que o uso passa a ser uma forma de fuga, de prazer temporário e de preenchimento de um vazio existente (MATOS, 2018).

A nova forma de pensar e lidar com o processo de sofrimento psíquico no Brasil, orienta a implantação de serviços substitutivos ao modelo asilar e que sejam portas abertas às demandas de saúde mental e de álcool e outras drogas do território, como também para identificar populaçóes específicas e mais vulneráveis, as quais devem ser objeto de estratégias diferenciadas de cuidado. Foi possível verificar que o CAPS-ad III, de maneira geral, atua com "porta aberta" e é a entrada da rede de saúde mental da região referenciada, promovendo ações que são sustentadas pelas evidências científicas, no que se refere ao acolhimento, ao acesso, à escuta qualificada, ao planejamento do PTS, à técnica e à reorientação de serviços (BALLARIN et al., 2011; SALLES; SILVA, 2017; SILVA; CID; MATSUKURA, 2018).

Quanto à elaboração do PTS dos usuários em situação de rua, os resultados demonstraram não haver um consenso sobre esta questão; algumas profissionais referiram náo encontrar dificuldades adicionais na elaboração do PTS quando se tratam de PSR; outras já referiram ter dificuldades. Tais dificuldades podem estar relacionadas às mudanças que ocorreram nos serviços diante do novo modelo de cuidado, exigindo uma revisão de saberes e práticas, ampliando o foco da intervenção para além do sintoma relatado, trazendo para a clínica os aspectos sociais e de história de vida das pessoas, com a missão de cumprir com os pressupostos da reabilitação psicossocial fundamentados pela clínica ampliada (VASCONCELOS et al., 2016). Este novo modelo de cuidado se encontra ainda em processo de implantação, revelando fragilidades persistentes da rede socioassistencial e das políticas públicas voltadas para populaçóes vulneráveis, como as PSR, e que fazem uso problemático de álcool e outras drogas; a articulação intersetorial nestes casos, se torna ainda mais necessária para a garantia de direitos, seja de saúde, moradia, assistência social, trabalho, entre outros.

$\mathrm{O}$ acolhimento integral (leitos de retaguarda para desintoxicação existentes nos CAPS-ad III - 24h) foi um recurso utilizado por todos os participantes antes de serem encaminhados para a UA ou mesmo durante sua permanência. Torna-se indispensável sua utilização nestes casos de maior complexidade clínica e social, uma vez que o cuidado oferecido é contínuo e, desde sua entrada, se inicia o processo de participação dos usuários das atividades do CAPS-ad III (VAINER, 2016).

Nos casos em que o usuário "não quer sair da situação de rua" - compreendido como um processo de desfiliação, segundo Castel (1995), em que há uma situação de perda de direitos sociais e de progressivas rupturas de redes sociais, onde a rua passa a ser o local de moradia e de trabalho, permitindo uma articulaçáo do cotidiano deste usuário em torno desta nova realidade - as profissionais de terapia ocupacional referiram utilizar como estratégia terapêutica de reduçáo de danos o encaminhamento para o acolhimento diurno, onde o usuário permanece apenas o dia no serviço e a noite pode retornar para a rua. Neste caso, o ganho terapêutico não está na redução ou interrupção total do uso de drogas, mas no auxílio à reorganizaçáo do cotidiano e das atividades de vida diária do usuário (GALHEIGO, 2003), considerando, inclusive como ganho, o tempo em que ele passa no serviço e que não está fazendo uso de álcool ou de outras drogas (CONTE et al., 2004). Nesse sentido, o trabalho articulado dos profissionais do CAPS-ad III com as equipes de Consultório na Rua torna-se fundamental para o processo de aproximação da rede de cuidado a estes usuários, sensibilizando-os para o tratamento e viabilizando possíveis mudanças em seu cotidiano com vistas à melhora de sua qualidade de vida por meio do acesso à saúde e à assistência social, conforme sugerido pela Profissional 2 em uma de suas falas.

Os usuários destacaram a importância dos profissionais do serviço, considerando-os como pessoas fundamentais para o seu tratamento e demonstrando relação de confiança e vínculo, porém nâo conseguiram explicar a especificidade do terapeuta ocupacional, pontuando apenas como "ocupar a mente" e "trabalhar 
metas e objetivos" O conceito de ocupação é central para os terapeutas ocupacionais e decorre de como desenvolvem sua intervenção; o termo ocupação pode ser utilizado como atividade, ou como papéis ocupacionais produtivos; no entanto, ambos devem dar sentido à vida humana cumprindo com o seu papel terapêutico para a recuperaçấo e central para a saúde e o bem-estar (SALLES; MATSUKURA, 2016). É, ainda, um desafio para os terapeutas ocupacionais atuarem com pessoas que apresentam necessidades de saúde interrelacionadas sobremaneira com carências sociais, reveladas pela falta de acesso a direitos fundamentais, como moradia e emprego, tornando o planejamento e a execuçáo das açôes de cuidado um processo complexo e que depende do acúmulo de diferentes saberes (SOUZA; PEREIRA; GONTIJO, 2014).

Ao identificar a necessidade de se criar estratégias para a inclusão de novos e diversos saberes em seu contexto de atuação, a terapia ocupacional passa, entáo, a ser "credenciada" como partícipe neste cenário de práticas interdisciplinares; sua contribuição se revela a partir do momento em que, ao longo de sua história, o processo terapêutico ocupacional rompe com uma prática diretiva com foco na doença e incorpora novas tecnologias oriundas de outros campos do conhecimento, para além da saúde, empodera os usuários nas tomadas de decisões sobre seu PTS, democratiza a assistência atuando extramuros, e desloca seu foco da doença para a promoçáo de saúde mental e reinserção social (ALMEIDA; TREVISAN, 2011). Além disso, a própria Prática Centrada no Cliente dialoga com outros campos do conhecimento, uma vez que prioriza no processo terapêutico áreas do desempenho ocupacional referentes ao lazer, produtividade e autocuidado, que fazem sentido para o usuário naquele momento e contexto de vida (MÂNGIA, 2002). Nesse sentido, a percepção dos próprios terapeutas ocupacionais acerca do trabalho interdisciplinar e a visão de sua especificidade neste novo contexto de atuação, passa a ser, ao mesmo tempo, um desafio e um alento, uma vez que mesmo que as dificuldades se manifestem, encontram respaldo teórico e prático para subsidiar suas práticas.

Um dos principais objetivos dos serviços de saúde mental se refere à reinserção social dos usuários. A terapia ocupacional no cuidado das PSR e em uso problemático de álcool e outras drogas deve lançar mão de estratégias que busquem reconstruir processos de ressocialização e vínculos dentro e fora do espaço institucional (MALFITANO et al., 2014), por meio de atividades grupais, oficinas, rodas de conversa, visitas domiciliares, acompanhamento terapêutico, estratégias de cuidado interdisciplinar e intersetorial, projetos de geraçáo de renda e outros, criando espaços de experimentação e aprendizagem, explorando reflexóes e subjetividades que os aproximam de seus territórios e das relaçôes de conflitos e afeto nele presentes (SABINO et al., 2017; ASSAD; PEDRÃO; CIRINEU, 2016). Além disso, o terapeuta ocupacional deve oferecer reais possibilidades para os usuários exercitarem sua participação social com autonomia, por meio da oferta do acesso a bens e direitos sociais rompendo com a lógica excludente e alienante dos processos terapêuticos circunscritos ao espaço institucional (CASTRO et al., 2001). As atividades realizadas pelo terapeuta ocupacional com PSR e em uso problemático de álcool e outras drogas devem enriquecer, reestruturar, integrar e fortalecer os sentimentos da vida dos usuários, lançando mão de diferentes linguagens, sejam elas artísticas, corporal ou literária, com vistas ao favorecimento da reconstrução da cidadania e da reinserção social, da melhora/retorno das relaçóes familiares e sociais, e que devem ir além de uma abordagem exclusivamente individual, mas considere pontos coletivos e territoriais ao longo do processo de cuidado (SILVA et al., 2015).

Sabe-se, contudo, que é um desafio para os serviços e para os terapeutas ocupacionais contemplarem as singularidades de cuidado desta população, que vão desde a essencial disponibilidade de materiais, recursos e equipamentos adequados à prática do profissional, até a própria capacitação destes terapeutas ocupacionais para atenderem à complexidade de demandas que estes usuários apresentam como necessidades de saúde. A articulação com as redes sociais de suporte, assim como a mediaçáo de conflitos entre usuários e seus familiares, exigem uma multiplicidade de saberes e práticas:

[...] os objetivos terapêuticos ocupacionais estão pautados em dimensóes humanas impossíveis de serem segmentadas, visando redimensionamento dos projetos de vida, promoção e produção de vida. O que revela também desafios de ordem macrossocial que devem ser considerados (SILVA et al., 2015, p. 332).

O que se pode destacar a partir deste e de outros estudos, é que as estratégias utilizadas pelas terapeutas ocupacionais na relação com as pessoas em situação de rua e em uso problemático de álcool e outras drogas, perpassam os campos da saúde e do social, e se sustentam nos conhecimentos sobre a atividade humana para a construção do cuidado à luz dos pressupostos da reabilitação psicossocial. Ainda, 
cabem a estas terapeutas ocupacionais a atuação em defesa das políticas sociais e de saúde para o fortalecimento de açóes e pesquisas que busquem diminuir desigualdades e promover acesso a direitos de uma forma mais justa e digna (MUÑOZ, 2014; LOPES et al., 2008).

\section{Conclusão}

A reinserção social de pessoas em situação de rua e em uso problemático de álcool e outras drogas é um desafio presente para terapeutas ocupacionais e demais profissionais que atuam neste campo.

As práticas cotidianas enquanto lugar de ação do terapeuta ocupacional junto a essa população, devem ser pensadas a partir de seu contexto histórico, cultural e social, favorecendo o cuidado integral e em consonância com a complexidade da demanda. $\mathrm{O}$ avanço da intersecção entre os saberes da saúde e do social possibilitarão a expansão do fazer terapia ocupacional, no sentido de lhe atribuir a devida magnitude revelada no processo de produção de vida que se dá a partir de sua relação com pessoas que se beneficiam de seu conhecimento.

\section{Referências}

ALMEIDA, D. T.; TREVISAN, E. R. Estratégias de intervenção da terapia ocupacional em consonância com as transformaçóes da assistência em saúde mental no Brasil. Interface - Comunicação, Saúde, Educação, Botucatu, v. 15, n. 36, p. 299-308, 2011.

ALVAREZ, A. M. S.; ALVARENGA, A. T.; RINA, S. C. S. A. D. Histórias de vida de moradores de rua, situaçóes de exclusão social e encontros transformadores. Saúde e Sociedade, São Paulo, v. 18, n. 2, p. 259-272, 2009.

AMARANTE, P. Saúde mental e atenção psicossocial. Rio de Janeiro: Editora Fiocruz, 2007.

ANDRADE, T. et al. 'What a pity!'-Exploring the use of 'pitilho'as harm reduction among crack users in Salvador, Brazil. Drugs: Education Prevention and Policy, Abingdon, v. 18, n. 5, p. 382-386, 2011.

ASSAD, F. B.; PEDRÃO, L. J.; CIRINEU, C. T. Estratégia de cuidado utilizada por terapeutas ocupacionais em Centros de Atenção Psicossocial. Cadernos de Terapia Ocupacional da UFSCar, São Carlos, v. 24, n. 4, p. 743-753, 2016.

BALLARIN, M. L. G. S. et al. Percepção de profissionais de um CAPS sobre as práticas de acolhimento no serviço. $O$ Mundo da Saúde, São Paulo, v. 35, n. 2, p. 162-168, 2011.

BARDIN, L. Análise de conteúdo. Lisboa: Ediçóes 70, 2009.

BOCCARDO, A. C. S. et al. O projeto terapêutico singular como estratégia de organização do cuidado nos serviços de saúde mental. Revista de Terapia Ocupacional da Universidade de São Paulo, São Paulo, v. 22, n. 1, p. 85-92, 2011.

BRASIL. Decreto no 7.053 de 23 de dezembro de 2009. Institui a Política Nacional para a População em Situação de Rua e seu Comitê Intersetorial de Acompanhamento e Monitoramento, e dá outras providências. Diário Oficial [da] República Federativa do Brasil, Poder Executivo, Brasília, DF, 23 dez. 2009a.

BRASIL. Ministério do Desenvolvimento Social e Combate à Fome. Pesquisa Nacional sobre a População Nacional em Situação de Rua. Brasília: MDS, 2009b.

BRASIL. Portaria GM/MS no 3088, de 23 de dezembro de 2011. Institui a Rede de Atenção Psicossocial para pessoas com sofrimento ou transtorno mental e com necessidades decorrentes do uso de crack, álcool e outras drogas, no âmbito do Sistema Único de Saúde. Diário Oficial [da] República Federativa do Brasil, Poder Executivo, Brasília, DF, 23 dez. 2011.

CASTEL, R. Les métamorphoses de la question sociale: une chronique du salariat. Paris: Gallimard, 1995.

CASTRO, E. D.; LIMA, E. M. F. A.; BRUNELLO, M. I. B. Atividades humanas e Terapia Ocupacional. In: DE CARLO, M. M. R. P.; BARTALOTTI, C. C. Terapia Ocupacional no Brasil: fundamentos e perspectivas. São Paulo: Plexus, 2001. p. 41-59.

CONTE, M. et al. Redução de Danos e Saúde mental na Perspectiva da atenção básica. Boletim da Saúde, Porto Alegre, v. 18, n. 1, p. 59-77, 2004.

FOUCAULT, M.; ALVAREZ-URÍA, F; VARELA, J. Microfisica del poder. Barcelona: La Piqueta, 1992.

GALHEIGO, S. M. O cotidiano na terapia ocupacional: cultura, subjetividade e contexto histórico-social. Revista de Terapia Ocupacional da Universidade de São Paulo, São Paulo, v. 14, n. 3, p. 104-109, 2003.

GALLASSI, A. D. et al. Characteristics of clients using a community-based drug treatment service ('CAPS-AD') in Brazil: an exploratory study. International Journal of Drug Policy, London, v. 31, p. 99-103, 2016.

LOPES, R. E. et al. Juventude pobre, violência e cidadania. Saúde e Sociedade, São Paulo, v. 17, n. 3, p. 63-76, 2008.

MALFITANO, A. P. S. et al. Social occupational therapy: conversations about a Brazilian experience. Canadian Journal of Occupational Therapy, Canada, v. 81, n. 5, p. 298-307, 2014

MALFITANO, A. P.; BIANCHI, P. C. Terapia Ocupacional e atuação em contextos de vulnerabilidade social: distinçóes e proximidades entre a área social e o campo de atenção básica em saúde. Cadernos de Terapia Ocupacional da UFSCar, São Carlos, v. 21, n. 3, p. 563-574, 2013.

MÂNGIA, E. F. Contribuiçóes da abordagem canadense "Prática de Terapia Ocupacional Centrada no Cliente" e dos autores da desinstitucionalização italiana para a Terapia Ocupacional em Saúde Mental. Revista de Terapia 
Ocupacional da Universidade de São Paulo, São Paulo, v. 13, n. 3, p. 15-21, 2002.

MÂNGIA, E. F; MURAMOTO, M. Integralidade e construçáo de novas profissionalidades nos contexto dos serviços substitutivos de saúde mental. Revista de Terapia Ocupacional da Universidade de São Paulo, São Paulo, v. 17, n. 3, p. 115-122, 2006.

MATOS, A. C. N. População em situação de rua: a drogadição como escape para fuga da realidade. Psicologia. pt, Porto, v. 1, n. 1, p. 1-11, 2018.

MINAYO, M. C. S.; SANCHES, O. Quantitative and qualitative methods: opposition or complementarity? Cadernos de Saúde Pública, Rio de Janeiro, v. 9, n. 3, p. 237-248, 1993.

MUÑOZ, C. G. M. La labor de la terapia ocupacional en el marco de los determinantes sociales de la salud en Chile. Revista Chilena de Terapia Ocupacional, Chile, v. 14, n. 1, p. 73-80, 2014.

PAIVA, I. K. S. et al. Direito à saúde da população em situação de rua: reflexóes sobre a problemática. Ciência \& Saúde Coletiva, Rio de Janeiro, v. 21, n. 8, p. 25952606, 2016.

SABINO, J. S. et al. As açôes da terapia ocupacional com adolescentes em situação de vulnerabilidade social: uma revisão de literatura. Cadernos Brasileiros de Terapia Ocupacional, São Carlos, v. 25, n. 3, p. 627-640, 2017.

SALLES, D. B.; SILVA, M. L. Percepção de profissionais da área de saúde mental sobre o acolhimento ao usuário de substância psicoativa em CAPS-ad. Cadernos Brasileiros de Terapia Ocupacional, São Carlos, v. 25, n. 2, p. 341349, 2017.

SALLES, M. M.; MATSUKURA, T. S. O uso dos conceitos de ocupação e atividade na Terapia Ocupacional: uma revisão sistemática da literatura. Cadernos de Terapia Ocupacional da UFSCar, São Carlos, v. 24, n. 4, p. 801-810, 2016.

SILVA, C. R. et al. Mapeamento da atuação do terapeuta ocupacional nos Centros de Atenção Psicossocial Álcool e Drogas (CAPS ad) do interior do estado de São Paulo. Cadernos de Terapia Ocupacional da UFSCar, São Carlos, v. 23, n. 2, p. 321-324, 2015.

SILVA, F. P. D.; FRAZÃO, I. D. S.; LINHARES, F. M. P. Práticas de saúde das equipes dos Consultórios de Rua. Cadernos de Saúde Pública, Rio de Janeiro, v. 30, n. 4, p. 805-814, 2014

SILVA, I. C. N. et al. Representaçôes sociais do cuidado em saúde de pessoas em situação de rua. Revista da Escola de Enfermagem da USP, São Paulo, v. 52, n. e03314, p. $1-7,2018$

SILVA, J. F.; CID, M. F. B.; MATSUKURA, T. S. Atenção psicossocial de adolescentes: a percepção de profissionais de um CAPSi. Cadernos Brasileiros de Terapia Ocupacional, São Carlos, v. 26, n. 2, p. 329-343, 2018.

SOUZA, V. C. A.; PEREIRA, A. R.; GONTIJO, D. T. A experiência no serviço de Consultório de Rua na perspectiva dos profissionais: contribuiçóes para a atençáo ao usuário de álcool e outras drogas. Cadernos de Terapia Ocupacional da UFSCar, São Carlos, v. 22, p. 37-47, 2014. Suplemento Especial.

VAINER, A. A. Demanda e Utilização do Acolhimento Noturno em Centro de Atenção Psicossocial III na Cidade do Rio de Janeiro. 2016. 92 f. Tese (Doutorado em Saúde Pública) - Fundaçáo Oswaldo Cruz, Rio de Janeiro, 2016.

VARANDA, W.; ADORNO, R. C. F. Descartáveis urbanos: discutindo a complexidade da populaçáo de rua e o desafio para políticas de saúde. Saúde e Sociedade, São Paulo, v. 13, n. 1, p. 56-69, 2004.

VASCONCELOS, A. C. M. et al. Relaçóes familiares e dependência química: uma revisão de literatura. Revista Brasileira de Ciências da Saúde, João Pessoa, v. 19, n. 4, p. 321-326, 2015.

VASCONCELOS, M. G. F. et al. Projeto terapêutico em Saúde Mental: práticas e processos nas dimensôes constituintes da atenção psicossocial. Interface - Comunicação, Saúde, Educação, Botucatu, v. 20, n. 57, p. 313-323, 2016.

\section{Contribuição dos Autores}

Fernanda Oliveira Mota: concepçáo do trabalho, coleta, organizaçáo e análise dos dados e redaçáo do texto. Rafaela Maria Alves Martins Fonseca: análise dos dados, redaçáo e revisão do texto. Josenaide Engracia dos Santos: análise dos dados e revisão do texto. Andrea Donatti Gallassi: concepção do trabalho, orientação, análise dos dados, redação e revisão do texto. Todas as autoras aprovaram a versão final do artigo.

\section{Notas}

${ }^{1} \mathrm{O}$ nome real foi substituído por este fictício para preservar o sigilo.

${ }^{2} \mathrm{O}$ conceito de reinserção social aqui utilizado tem como referência o apontado por Mângia e Muramoto (2006, p. 116): "Para a reabilitação psicossocial e mais especificamente para a terapia ocupacional, o desafio da inserção social de pessoas vulneráveis e o desenvolvimento de formas de convívio com a diferença exigem transformaçóes profundas nos modos de conceber o cuidado e organizar os serviços em confronto com as concepçôes e estratégias tradicionais o que implica na definição de novos perfis profissionais".

${ }^{3} \mathrm{O}$ nome real foi substituído por este fictício para preservar o sigilo. 